\title{
Editorial
}

\section{The treatment of primary pulmonary hypertension}

Primary pulmonary hypertension caused by narrowing of the small resistance arteries, well described by Wood, ${ }^{1}$ is usually taken to indicate the absence of a cardiac or respiratory cause for the condition. ${ }^{23}$ When the major pulmonary arteries are obstructed the disorder is often called "chronic thromboembolic pulmonary hypertension" although a history of pulmonary embolism is rare and most of these cases probably result from a previous pulmonary arteritis sometimes associated with systemic arteritis in the so-called Takayasu syndrome. ${ }^{4}$ Postcapillary pulmonary hypertension caused by obliteration of pulmonary veins and venules (pulmonary veno-occlusive disease), is rare and rapidly fatal especially in children and young people. ${ }^{5}$ It closely resembles pre-capillary primary pulmonary hypertension from which it can sometimes be distinguished clinically if the lung fields show small patches of interstitial oedema or a cloudy background or pulmonary arteriography shows an abnormal venous phase.

\section{Causes of primary pulmonary hypertension}

Primary pulmonary hypertension can be a complication of systemic lupus, ${ }^{67}$ scleroderma,${ }^{8}$ CREST syndrome, ${ }^{9}$ and mixed connective tissue disease ${ }^{10}$ and in patients without such features there is often a hint of an autoimmune origin in the form of Raynaud's phenomenon," thrombocytopenia, or a history of uveitis. Rare patients with pulmonary veno-occlusive disease have vasculitic skin lesions, which also suggest a possible immunological basis, but the origin of the disease remains obscure. ${ }^{12}$

Wood first suggested that primary type pulmonary hypertension had a vasoconstrictive basis. He showed that pulmonary artery pressure was reduced in patients with mitral valve disease after intravenous aminophylline and tolazoline and the intra-pulmonary infusion of acetylcholine. ${ }^{1314}$ The pathological features that were also thought to indicate a vasoconstrictive aetiology were hypertrophy of the media of small muscular arteries and extension of muscle into pulmonary arterioles together with dilatation (plexiform) lesions. ${ }^{11}$ These studies showed that a few patients had a thrombotic arteriopathy which at the time was believed to have resulted from chronic microthromboembolism-though there was no evidence for this. ${ }^{11}$ In further work, the two histological types, thrombotic and plexiform, were again separated and it was suggested that the thrombotic form might represent thrombosis in situ, possibly as a consequence of a small vessel arteritis. ${ }^{1516}$ Open lung biopsy has not been much used in the United Kingdom because of its failure to influence therapeutic strategies: but it was part of the protocol in the American Primary Pulmonary Hypertension Registry, which was notable for the high complication rate of biopsy in these patients. The course of the thrombotic form, which affects both male and female patients, was sometimes prolonged; plexiform arteriopathy was almost exclusively confined to young female patients. ${ }^{17}$

\section{Current knowledge}

Any rigid distinction between two histological types was found to be unsound in a recent study of familial primary pulmonary hypertension in which both thrombotic and plexiform lesions were found within patients and among the affected families. ${ }^{18}$ Both types of lesion were also found in pulmonary hypertension associated with the Eisenmenger syndrome, ${ }^{19}$ collagen vascular diseases, ${ }^{6-10}$ in drug induced pulmonary hypertension in the aminorex fumarate epidemic ${ }^{20}$ in the toxic oil syndrome, ${ }^{21}$ and associated with cirrhosis. ${ }^{22}$

A high frequency of plexiform lesions does seem to be associated with a more rapidly fatal course ${ }^{17}$ and fibroblast migration through defects in the inner elastic lamina, probably the result of endothelial interruption, may herald prodromal lesions. ${ }^{23}$ In addition, it has been suggested that the pulmonary vascular bed maintains its low resistance through the action of endothelium derived relaxation factor with plexiform arteriopathy resulting from the failure of the production or release of this factor; vasodilatation by acetylcholine (in its endothelium dependent role) has been cited as parallel evidence for this effect. ${ }^{16}$ Endothelial cell injury as seen in rats after crotalaria ingestion, ${ }^{24}$ or immune-mediated damage of the endothelium, as in collagen vascular disease ${ }^{25}$ may be responsible for myofibroblast migration and proliferation, which would explain the development of the thickening of the medial coat $^{16}$ rather than vasoconstriction. These effects or the advanced stage of the disease when patients are first seen may explain the frequently disappointing response to treatment with vasodilators, which has been the only available medical treatment apart from anticoagulants. ${ }^{26}$ The use of anticoagulants was associated with an apparent improvement in survival in a large retrospective study that did not distinguish between subgroups. ${ }^{27} \mathrm{It}$ is possible that long term anticoagulants may reduce the incidence of thrombosis in situ or reduce thromboembolism secondary to the low cardiac output. ${ }^{26}$

\section{Treatment with vasodilators}

The association with Raynaud's disease and rare reports of regression lent support to the theory of vasoconstriction and to the extensive use of vasodilators. ${ }^{131428-49}$ None the less, vasodilators given acutely may be dangerous if they cause only systemic and not pulmonary vasodilatation..$^{26} 36$ They may be helpful if a fall in pulmonary vascular resistance allows right and thus left ventricular output to increase. Most vasodilators predominantly affect the systemic resistance vessels and will only be tolerated in patients with pulmonary hypertension if there is a sufficient effect also on the pulmonary vessels to permit the cardiac output to rise and maintain blood pressure. Virtually every vasodilator has been tried and the results published. Though nifedipine has found most favour, ${ }^{31378}$ it too is not without its disastrous side effects. This is because its depressant effect on myocardial contractile force may be unmasked and this can cause circulatory collapse if the right ventricular afterload is not reduced.

Acute testing of vasodilators has been used to predict benefit and prevent untoward reactions. ${ }^{43749}$ These studies have shown that those patients who are capable of responding tend to respond to whatever vasodilator is given-a favourable response to prostacyclin was associated with a 
good response to nifedipine also. ${ }^{47}$ So long term infusions of prostacyclin into the pulmonary artery, a treatment that is highly demanding of both patient and doctor and not without complications, ${ }^{45}$ is not justified. Most patients will not tolerate high doses of calcium channel blocking drugs but remarkable reductions in pulmonary artery pressure and resistance were achieved in some patients treated with high doses of diltiazem or nifedipine and the improvement was sustained over months. ${ }^{46}$ These successes and rare cases of spontaneous improvement ${ }^{5051}$ have sustained the use of these usually unsuccessful and poorly tolerated agents. ${ }^{52}$

\section{Outcome}

All of the studies have shown a wide variation in survival, from months up to 30 or even 40 years from diagnosis. ${ }^{27} 44$ This has been used as evidence for diverse aetiologies but it could equally well result from the same cause having disastrous consequences, as in some young females who show major vascular consequences and a mainly plexiform arteriopathy, or a more stable protracted course in patients with the less severe changes of a mainly thrombotic arteriopathy. Both could result from a vasculitic illness. Studies of the natural history of the disease showed that the sickest patients survived the shortest time. Right ventricular failure is the single most important determinant of prognosis. ${ }^{44}$ This has been recorded in published reports which detailed a right atrial pressure $>6 \mathrm{~mm} \mathrm{Hg}$, a stroke volume index of $<22 \mathrm{ml} / \mathrm{m}^{2}$, a cardiac index $<2.81 / \mathrm{min} /$ $\mathrm{m}^{2}$, or a pulmonary artery saturation $<63 \%$ as adverse prognostic features ${ }^{2753-55}$ but did not emphasise right ventricular failure as such. Not surprisingly, the pulmonary artery pressure is usually not a determinant because it fails to rise once the output starts to fall as the right ventricle fails.

More recent work has used echocardiography to measure these indices ${ }^{56}$ and it may be more informative than catheterisation in showing right ventricular function and pressure serially, tricuspid regurgitation, and when right ventricular systolic or diastolic pressure is higher than the systemic pressure. A low cardiac output, abnormal tricuspid Doppler diastolic filling patterns due to prolonged isovolumic relaxation, tachycardia, and curtailed right ventricular filling time may also be found.

These omens of poor or deteriorating right ventricular function indicate a short life expectancy in patients with primary type pulmonary hypertension; most of these patients do not survive three years from the time of presentation. At present, heart/lung transplantation offers the only hope of longer term survival with restoration of their quality of life. Improved management of rejection and infection with newer drugs and routine bronchoscopic surveillance to detect these complications early has resulted in much better survival. Three year survival is now $65 \%$ and the incidence of obliterative bronchiolitis is lower. ${ }^{57}$ These patients with primary type pulmonary hypertension who have no disease elsewhere and who are young and otherwise fit are most likely to benefit from this procedure. Moreover, their hearts can be used in recipients with pulmonary hypertension complicating left heart failure.

\section{The future}

Future treatments are likely to arise as developments in vascular and cell biology lead to a better understanding of the growth factors that determine the proliferative responses to endothelial injury. ${ }^{58}$ Future understanding of adhesion molecules such as fibronectin and von Willebrand factor which influence cell migration and proliferation, ${ }^{59}$ of charge related microvascular injury, ${ }^{60}$ and vascular remodelling after injury ${ }^{61}$ may lead to more successful treatments. These may be particularly relevant if primary type pulmonary hypertension follows a pulmonary vasculitis which, if it is not rapidly fatal, can achieve haemodynamic stability. It is unfortunate that delayed initial presentation may still inhibit the use of potentially successful agents. It seems that we are a long way from being able to treat primary type pulmonary hypertension effectively because of the late presentation of most of the patients. Only the fortunate few, in spite of or because of our management, will show stability or improvement. For most of them heart/lung or single lung transplantation is likely to remain the best available treatment.

Clinical Cardiology Unit, NEAL G UREN Department of Medicine, Hammersmith Hospital, Du Cane Road, London W12 ONN

1 Wood P. Pulmonary hypertension. Br Med Bull 1952;8:348-53.

2 Hughes JD, Rubin LJ. Primary pulmonary hypertension. Medicine (Baltimore) 1986;65:56-72.

3 Rich S. Primary pulmonary hypertension. Prog Cardiovasc Dis 1988;31: 205-38.

4 Kawai C, Ishikana K, Kato M, et al. "Pulmonary pulseless disease": pulmonary involvement in so-called Takayasu's disease. Chest 1978;73: pulmo 65 .

5 Thadani U, Burrow C, Whitaker W, et al. Pulmonary veno-occlusive disease. QJ Med 1975;44:133-59.

6 Wakaki $\mathrm{K}$, Koizumi F, Fukase $\dot{M}$. Vascular lesions in systemic lupus erythematosus with primary pulmonary hypertension. Acta Pathol Jpn 1984;34:593-604.

7 Asherson RA, Oakley CM. Pulmonary hypertension and systemic lupus erythematosus. $J$ Rheumatol 1986;13:1-5.

8 Young RH, Mark GJ. Pulmonary vascular changes in scleroderma. Am J Med 1978;64:998-1004.

9 Salerni R, Rodnan GP, Leon DF, et al. Pulmonary hypertension in the CREST syndrome variant of progressive systemic sclerosis (scleroderma). Acta Intern Med 1977;86:394-9.

10 Sullivan WD, Hurst DJ, Harmon CE, et al. A prospective evaluation emphasizing pulmonary involvement in patients with mixed connective tissue disease. Medicine (Baltimore) 1984;63:92-107.

11 Wagenvoort CA, Wagenvoort N. Primary pulmonary hypertension: a pathologic study of the lung vessels in 156 clinically diagnosed cases. Circulation 1970;42:1163-84.

12 Sanderson JE, Spiro SG, Hendry AT, Turner-Warwick M. A case of pulmonary veno-occlusive disease responding to treatment with azathioprine. Thorax 1977;32:140-8.

13 Wood $\mathrm{P}$. The vasoconstrictive factor in pulmonary hypertension. In: Adams WR, Veith I, eds. Pulmonary circulation. New York: Grune and Stratton, WR, Veith I,
1959:294-301.

14 Wood P. Pulmonary hypertension with special reference to the vasoconstrictive factor. Br Heart $J$ 1958;20:557-70.

15 Bjornsson J, Edwards WD Primary pulmonary hypertension: a histologic study of 80 cases. Mayo Clin Proc 1985;60:16-25.

16 Rich S, Brundage B. Pulmonary hypertension: a cellular basis for understanding the pathophysiology and treatment. J Am Coll Cardiol 1989;14: 545-50.

17 Pietra GG, Edwards WD, Kay M, et al. Histopathology of primary pulmonary hypertension. A qualitative and quantitative study of pulmonary blood vessels from 58 patients in the National Heart, Lung, and Blood Institute, Primary Pulmonary Hypertension Registry. Circulation 1989;80:1198-206.

18 Loyd JE, Atkinson JB, Pietra GG, Virmani R, Newman JH. Heterogeneity of pathologic lesions in familial primary pulmonary hypertension. Am Rev Respir Dis 1988;138:952-7.

19 Heath D, Edwards JE. The pathology of hypertensive pulmonary vascular disease: a description of six grades of structural changes in the pulmonary arteries with special references to congenital cardiac septal defects. Circulation 1958;18:533-47.

20 Gurtner HP. Aminorex and pulmonary hypertension. Cor Vasa 1985;27:160-71.

21 Gomez-Sanchez MA, Mestre de Juan M, Gomez-Pajuelo C, Lopez JI, Diaz de Atauri M, Martinez-Tello FJ. Pulmonary hypertension due to toxic oil de Atauri M, Martinez-Tello FJ. Pulmonary hypertension d

22 Morrison EB, Gaffrey FA, Eigenbrodt EH, Reynolds RC, Buja LM. Severe pulmonary hypertension associated with macronodular (post-necrotic) pulmonary hypertension associated with macronodular (post-necrot

23 Heath D, Smith P, Gosney J, et al. The pathology of the early and late stages Heath $\mathrm{D}$, Smith $\mathrm{P}$, Gosney J, et al. The pathology of the early and lar
of primary pulmonary hypertension. Br Heart J 1987;58:204-13 of primary pulmonary hypertension. Br Heart $J$ 1987;58:204-13. islop A, Reid L. Arterial changes in Crotolaria Spectabilis-ind

pulmonary hypertension in rats. Br J Exp Pathol 197.4;55:153-7.
. Rich S, Kieras K, Hart K, et al. Antinuclear antibodies
pulmonary hypertension. J Am Coll Cardiol 1986;8:1307-11.

26 Oakley CM. Management of primary pulmonary hypertension. Br Heart J 1985;53:1-4.

27 Fuster V, Steele PM, Edwards WD, Gersh BJ, McGoon MD, Frye RL. Primary pulmonary hypertension: natural history and the importance of thrombosis. Circulation 1984;70:580-7.

28 Dresdale DT, Michtom RJ, Schultz M. Recent studies in primary pulmon- 
ary hypertension including pharmacodynamic observation on pulmonary vascular resistance. Bull NY Acad Med 1954;30:195-207.

29 Widimský J, Kasalický J, Dejdar R, Vysloužil Z, Lukeš M. Effect of reserpine on the lesser circulation in chronic pulmonary diseases. Br Heart $J$ 1962;24:274-8.

30 Landmark K, Refsum AM, Simonsen S, Storstein O. Verapamil and pulmonary hypertension. Acta Med Scand 1978;204:299-302.

31 Camerini F, Alberti E, Klugmann N, Salvi A. Primary pulmonary hypertension: effects of nifedipine. Br Heart $J$ 1980;44:352-6.

32 Rubin LJ, Peter RH. Oral hydralazine therapy for primary pulmonary hypertension. N Engl J Med 1980;302:69-73.

33 Watkins WD, Peterson MB, Crone RK, et al. Prostacyclin and prostaglandin $\mathrm{E}_{1}$ for severe idiopathic pulmonary artery hypertension. Lancet 1980;i: 1083 .

34 Rubin LJ, Groves BM, Reeves JT, Frosolono M, Handel F, Cato AE. Prostacyclin-induced pulmonary vasodilatation in primary pulmonary hypertension. Circulation 1982;66:334-8.

35 Kambara H, Fujimoto K, Wakabayashi A, Kawai C. Primary pulmonary hypertension: beneficial therapy with diltiazem. Am Heart $J$ 1981;101: 230-1.

36 Packer M, Greenberg B, Massie B, Dash H. Deleterious effects of hydralazine in patients with primary hypertension. N Engl J Med 1982;306:1326-31.

37 Rich S, Ganz R, Levy PS. Comparative effects of hydralazine, nifedipine and amrinone in primary pulmonary hypertension. Am $J$ Cardiol 1983;52:1104-9.

38 Douglas JS. Hemodynamic effects of nifedipine in primary pulmonary hypertension. J Am Coll Cardiol 1983;2:174-9.

39 McGoon MD, Vliestra MB. Vasodilator therapy for primary pulmonary hypertension. Mayo Clin Proc 1984;59:672-7.

40 Rich S, Brundage B, Levy PS. The effect of vasodilator therapy on the clinical outcome of patients with primary pulmonary hypertension. Circulation 1985;71:1191-6.

41 Packer $M$. Vasodilator therapy for primary pulmonary hypertension. Limitations and hazards. Ann Intern Med 1985;103.258-70.

42 Stumpe KO, Schmengler K, Bette L, et al. Persistent hemodynamic and clinical improvement after captopril in patients with pulmonary hypertension. Herz 1986;11:217-25.

43 Reeves JT, Groves BM, Turkevich D. The case for treatment of selected patients with primary pulmonary hypertension. Am Rev Respir Dis 1986;134:342-6.

44 Roskovec A, Montanes P, Oakley CM. Factors that influence the outcome of primary pulmonary hypertension. Br Heart $J$ 1986;55:449-58.

45 Jones DK, Higenbottam TW, Wallwork J. Treatment of primary pulmonary hypertension with intravenous epoprostenol (prostacyclin). Br Heart J
1987;57:270-8.

46 Rich S, Brundage B. High-dose calcium channel-blocking therapy for primary pulmonary hypertension: evidence for long-term reduction in pulmonary arterial pressure and regression of right ventricular hypertrophy. Circulation 1987;76:135-41.

47 Roskovec A, Stradling JR, Shepherd G, MacDermot J, Oakley CM, Dollery CT. Prediction of favourable responses to long term vasodilator treatmen of pulmonary hypertension by short term administration of epoprosteno (prostacyclin) or nifedipine. Br Heart J 1988;59:696-705.

48 Dantzker DR, D’Alonzo GE, Gianotti L, Fuentes F, Nickeson D, Emerson $M$. Vasodilators and primary pulmonary hypertension. Variability of long-term response. Chest 1989;95:1185-9.

49 Palevsky HI, Schloo BL, Pietra GG, et al. Primary pulmonary hypertension Vascular structure, morphometry, and responsiveness to vasodilator agents. Circulation 1989;80:1207-21.

50 Bourdillon PDV, Oakley CM. Regression of primary pulmonary hypertension. Br Heart J 1976;38:264-70.

51 Fujii A, Rabinovitch M, Matthews EC. A case of spontaneous resolution of idiopathic pulmonary hypertension. Br Heart $J$ 1981;46:574-7.

52 Packer $M$. Is it ethical to administer vasodilator drugs to patients with primary pulmonary hypertension? Chest 1989;95:1173-5.

53 Kanemoto N, Sasamoto H. Pulmonary hemodynamics in primary pulmonary hypertension. Jpn Heart J 1979;20:395-405.

54 Rich S, Levy PS. Characteristics of surviving and nonsurviving patients with primary pulmonary hypertension. Am J Med 1984;76:573-8.

55 Glanville AR, Burke CM, Theodore J, Robin ED. Primary pulmonary hypertension. Length of survival of patients referred for heart-lung transplantation. Chest 1987;91:675-81.

56 Eysmann SB, Palevsky HI, Reichek N, Hackney K, Douglas P. Twodimensional and doppler echocardiography and cardiac catheterization correlates of survival in primary pulmonary hypertension. Circulation 1989;79:353-60.

57 McCarthy PM, Starnes VA, Theodore J, Stinson EB, Oyer PE, Shumway NE. Improved survival after heart-lung transplantation. $J$ Thorac Cardiovasc Surg 1990;99:54-9.

58 Newman JH, Ross JC. Primary pulmonary hypertension: a look at the future. J Am Coll Cardiol 1989;14:551-5.

59 Ruoslahti E, Pierschbacher MD. New perspectives in cell adhesion: RGD and integrins. Science 1987;238:491-7.

60 Chang SW, Voelkel NF. Charge-related microvascular injury. Am Rev Respir Dis 1989;139:534-45.

61 Hales CA, Kradin RL, Brandstetter RD, Zhu Y. Impairment of hypoxic pulmonary artery remodelling by heparin in mice. Am Rev Respir Dis 1983;128:747-51. 